\title{
COMUNICAÇÃO DE ATITUDE: POR UMA NOVA POSTURA MERCADOLÓGICA
}

\section{Attitude Communication: a new marketing stance \\ Comunicación de la actitud: una nueva postura mercadologica}

\author{
Rodrigo Stéfani Correa ${ }^{1}$
}

\begin{abstract}
RESUMO
A "Comunicação de atitude" incorpora novos valores de responsabilidade social à linguagem publicitária que não podem ser confundidos com estratégias de marketing em ações emergenciais e pontuais de empresas que buscam simplesmente prestar um serviço de ajuda social. A "Comunicação de atitude" tratada neste artigo pretende trazer reflexões profundas do engajamento social de empresas que entendem a complexidade do mundo atual e se posicionam de forma institucional, integrada e interativa. Com isso, as investigações aqui realizadas têm o interesse de revelar o modo como as empresas podem participar dessa tomada de consciência incorporando em sua missão cultura, e na mentalidade de seus dirigentes atitudes que favorecem tanto os negócios quanto a qualidade de vida das pessoas, adotando posturas de responsabilidade social.
\end{abstract}

Palavras-chave: comunicação; atitude; responsabilidade social; propaganda.

\begin{abstract}
The Attitude Communication incorporates the new values of social responsibility in advertising language that can not be confused with marketing strategies in emergency actions and punctual to companies that seek simply to provide a welfare service. The Attitude Communication addressed in this article aims at bringing profound reflections on companies social engagement that understand the complexity of today's world and which are institutionally positioned in an, integrated and interactively way. Therefore, the investigations undertaken here have the interest of revealing the way companies in general may participate of conscious awareness by incorporating cultural aspects in their mission and attitudes which improve business as well as people's quality of life in their leader's mentality, by adopting social responsible stands.
\end{abstract}

Keywords: communication; attitude; social responsibility; advertising.

\section{RESUMEN}

La Comunicación de la Actitud incorpora nuevos valores de la responsabilidad social para el discurso de publicidad donde no puede confundirse con estrategias de comercialización en las medidas de emergencia y acciones ocasionales a las empresas que buscan simplemente proporcionar un servicio de bienestar. La Comunicación de la Actitud empreendidas en el presente artículo pretende aportar reflexiones de profundo compromiso social de las empresas que entienden la complejidad del mundo de hoy y adoptan una postura institucional, integrada e interactiva. Por lo tanto, las investigaciones realizadas aquí tienen el interés en revelar cómo las empresas pueden asumir en esta toma de conciencia con la adopción en su misión, en la cultura y la mentalidad de sus dirigentes las actitudes que favorecen tanto la empresa, cuando la calidad de vida de las personas asumiendo nuevas actitudes de la responsabilidad social.

Palabras clave: comunicación; actitud; responsabilidad social; publicidad.

\footnotetext{
${ }^{1}$ Rodrigo Stéfani Correa é Doutor em Comunicação pela Pontifícia Universidade Católica de São Paulo e coordenador dos cursos de Marketing e Publicidade \& Propaganda na Universidade Anhanguera (Uniderp), onde desenvolve suas pesquisas em conjunto com o Grupo de Pesquisa CNPq, Comunicação e Cultura: barroco e mestiçagem.rsccorrea@yahoo.com
} 
A comunicação social evoluiu muito no transcorrer do século XX para o século XXI, com a mudança da economia institucionalmente baseada na produção em escala para a economia focada nas necessidades e desejos do homem. $\mathrm{O}$ conceito de produto adquiriu um significado diferente na concepção capitalista que tomou o mundo contemporâneo, colocando o discurso publicitário em uma plataforma de notoriedade.

Segundo Philip Kotler (1996, p. 31), "A existência de necessidades e desejos humanos leva-nos ao conceito de que um produto é tudo aquilo capaz de satisfazer a um desejo". Nesse contexto, as necessidades comuns ao consumo focado exclusivamente em produtos impediram durante décadas a explosão de novos entendimentos que são essenciais para a adaptação de empresas à nova economia internacionalizada, quebrando antigas convenções funcionalistas, como a proposta pela pirâmide de Maslow², além de outras novas posturas mercadológicas que emergiram com as transformações no comportamento do homem no mundo industrializado.

À medida que a humanidade caminha para a década de 2010, evidenciam-se, com maior protuberância, os problemas éticos e culturais que crescem proporcionais ao número de empresas que pensam a comunicação como um fator estratégico e de necessidade social, pois o discurso publicitário deixou de ser um elemento exclusivo do composto do marketing (promoção), evoluindo das suas antigas origens, com base na distribuição e vendas, para uma filosofia mais complexa e comprometida com as exigências do consumidor internacionalizado.

Entende-se, dessa forma, que a comunicação social se desenvolveu de maneira mais capitalista no Brasil porque a publicidade encontrou no continente sul-americano um terreno fértil e muito exuberante para a oferta de produtos com diferentes características fisiológicas.
Afinal, no Brasil, a existência de matéria-prima em abundância favoreceu, consequentemente, o aumento no volume de ofertas de produtos e, na mesma escala, a utilização do recurso publicitário como ferramenta a serviço da força de venda.

Ao mesmo tempo em que a propaganda tornou-se um instrumento imprescindível para as estratégias de marketing, ela cresceu enraizada aos valores da cultura solar e mestiça existente no Brasil, como parte orgânica nas sociedades da América Latina. Dessa forma, o encontro da propaganda brasileira com a apurada técnica de marketing norte-americana, apoiada nos conceitos de vendas e promoção do século XXI, colocou em evidência um dos maiores conflitos acadêmicos e conceituais já discutidos em todos os tempos. Qual é o verdadeiro papel do discurso publicitário: vender ou informar/posicionar?

\section{O discurso publicitário dentro de uma nova ontologia}

O refinamento da publicidade moderna permite rigorosas observações acerca de suas características íntimas, com o favorecimento das técnicas de marketing encontradas no cenário publicitário latino-americano. O Brasil, por ser um país mestiço, dispõe de atributos que não são encontrados com tamanha generosidade em outros territórios. O sol, a terra fértil, as florestas, os recursos hídricos e minerais, sua gente com seus modos abertos e ruas borbulhantes, cercadas por comércios ambulantes e informais forneceram todas as partículas necessárias para a inspiração de grandes ideias no universo corporativo, além de fortalecer um repertório criativo, que mistura propaganda com o marketing, tornando-os quase sinônimos.

\footnotetext{
${ }^{2}$ Consultar a hierarquia de necessidades de Maslow, proposta por Abraham Maslow, em que as necessidades de nível mais baixo devem
} ser satisfeitas antes das necessidades de nível mais alto. Pode ser consultado em Maslow (1954, p. 80-106). 
No entanto, no Brasil, a propaganda científica praticada mais recentemente trouxe um novo peso para as atividades publicitárias exercidas na atual conjuntura, especialmente com a migração dos conceitos norte-americanos que povoaram o mercado por volta de 1930, inicialmente com o departamento de marketing da General Motors Company, que formou grandes nomes da propaganda no Brasil, dando origem às primeiras agências de publicidade e inserindo profissionais que são referência até hoje nesse mercado.

Em verdade, o primeiro grande passo no caminho do desejo e da necessidade de modificar, estruturar, profissionalizar e impulsionar a propaganda no Brasil deu-se com a vinda da J. Walter Thompson, em 1929, estabelecendo-se em São Paulo justamente para atender a General Motors, sua primeira conta no Brasil. Absorveu quase todos os profissionais do Departamento da GM e com eles passou a aplicar seus métodos, seus princípios e sua experiência plenamente comprovados (CASTELO BRANCO, 1990, p. 25-26).

Claude Hopinks (1966), um dos publicitários mais famosos e mais bem pagos de todo os tempos, define a propaganda científica como uma atividade atual, responsável pela construção das condições de vendas que formam um procedimento capaz de ser cartografado, servindo de bússola do conhecimento acurado, que orienta o curso mais rápido, mais seguro e mais barato para o êxito das vendas. Esse processo é meticulosamente organizado, comprovado por testes e experimentações, baseando-se em investigações que simulam o comportamento do consumidor e determinam técnicas padronizadas de venda.

Nesse contexto, pode-se alegar que:
Propaganda é promoção de vendas. Seus princípios são os princípios da habilidade de vender (salesmanship). Sucessos e malogros de duas atividades, devem-se a causas semelhantes. Assim, cada problema de propaganda deve ser resolvido segundo padrões de propaganda (HOPINKS, 1966, p. 26).

Deixando de lado os tradicionais conceitos epistemológicos que unem os termos publicidade e propaganda, já discutidos em abundância no meio acadêmico, e levando em consideração a relação de completude que essas palavras exercem uma sobre a outra, deve-se pensar em publicidade e propaganda como atividade organizacional das agências de publicidade, que, em suas atividades comerciais, veiculam campanhas publicitárias nas mídias tradicionais e alternativas. A partir daí, consideram-se as palavras de Harold D. Lasswell (1987) como um segundo ponto de vista. Para ele, a propaganda baseia-se nos símbolos para chegar a seu fim: a manipulação das atitudes coletivas. Assim, o uso de representações para produzir reações coletivas pressupõe uma ação de propaganda, mais popularmente denominada de persuasão.

Quaisquer que sejam os esforços para definir o sentido lógico da função da propaganda em nossa sociedade, nunca existirão argumentos suficientes ou tentativas plenas para desvencilhar a atividade lúdica da conscientização da massa à técnica exata do marketing, que já fundiu todos esses conceitos na América Latina.

A relevância das investigações que recaem sobre os aspectos culturais da sociedade mestiça brasileira e que são apresentadas nesse artigo implica uma nova linguagem produzida pela atividade profissional da comunicação, que difere daquela tradicional (de origem norteamericana), incorporada no século XX, quando a sociedade brasileira ainda se encontrava no processo de industrialização.

Dessa forma, levam-se em consideração as estruturas que as empresas utilizam 
para dialogar com a sociedade mediada pela linguagem do discurso publicitário e quais são os elementos de que esse discurso se apropria para promover sua ação de controle social.

Al Ries (1993), uma das principais autoridades no assunto, critica duramente a eficácia da propaganda como ferramenta de construção de marcas e venda de produtos. Ele afirma que a propaganda não é criativa, carece de credibilidade e está a serviço dos publicitários para a conquista de prêmios, e uma nova linguagem deve emergir para agregar valor à imagem das empresas no processo de construção de marca.

Ries defende a tese de que grandes marcas da atualidade - como Starbucks, The Body Shop, Wal-Mart, Linux, Red Bull, Microsoft, entre outras - foram construídas não com propaganda, mas graças ao trabalho de publicity (que em português pode ser entendido como o uso de ferramentas de argumentação nãocomercial, resultado do relacionamento com diversos públicos e divulgação orientada), uma espécie de linguagem que difere da propaganda e do marketing. Diante do fato exposto, entendese que no Brasil a propaganda tem perdido força em relação a outras competências do marketing, o que parece ser uma tendência irreversível.

Jeffrey Sharlach (2007, p. 13), um dos maiores especialistas em consultoria de comunicação organizacional com atuação na América Latina, incita essa discussão alegando que: "O básico da comunicação não mudou nesses últimos anos. O que alterou de forma determinante foram os meios como as pessoas se comunicam". Nessa direção, o presente trabalho eleva-se a apresentar para o meio acadêmico, em especial para aos estudantes de comunicação, uma nova estrutura de linguagem dita "social", partindo de uma reorganização nas posturas profissionais que englobam a atividade de criação e produção publicitária, não vinculada apenas a uma força de expressão em relação à comunicação persuasiva, mas à existência de múltiplos valores muito mais complexos que simplesmente a força estratégica de vendas. Adicionam-se a esses conceitos posturas práticas que não oferecem simplesmente produtos, entregam-se, além de produtos, valores morais, éticos, ambientais e culturais.

A estandardização do processo criativo na propaganda brasileira, produzida pela internacionalização das técnicas adotadas nas escolas de comunicação e nas agências de propaganda, automaticamente trouxe para sua tutela o sucesso das vendas de produtos que aconteceu em uma época não muito distante da atual, mas que revelava um cenário favorável à venda $e$ menos competitivo entre empresas. Contudo, as exigências sobre a eficácia da propaganda nos resultados de venda de produtos/serviços não deixaram de crescer e, hoje, cobram-se mais resultados em um ambiente muito mais competitivo e com crescente volume de produtos que disputam pelo mesmo segmento em pé de igualdade.

Nota-se, com isso, que a propaganda está atrelada às raízes do marketing tradicional, carregando a imagem do sucesso tardio como ferramenta eficaz de venda, junto com o caráter já ultrapassado dos anúncios de mercadorias e serviços, que tiveram seu apogeu no final do século XX. A propaganda ainda não se desvencilhou da imagem da profissão de status $e$ prestígio adquirida em décadas passadas. Esse procedimento, ao que tudo indica, não mais vem sendo absorvido pela sociedade com a mesma precisão que há 20 anos.

\section{A comunicação de atitude}

Diferentemente das ações isoladas que são chamadas de marketing social (ações promocionais) e de um discurso político neoliberal que recai sobre a propaganda, a comunicação de atitude assume uma relação de interatividade 
social ligada aos interesses capitalistas que não tem a pretensão de dar extensão ao conceito já consagrado do Terceiro Setor, mas o seu papel na sociedade moderna não deixa de conciliar o desenvolvimento econômico das organizações privadas com ações livres de objetivos mercadológicos e institucionais.

Distante do cinismo corporativo em querer mascarar um mundo extremamente competitivo e sem negar a existência de ações totalitárias que funcionam com critérios antidemocráticos, como descreve Wisconsin Madison (apud CHOMSKY, 1996, p. 7), a comunicação de atitude é uma resposta atual, dada por corporações que já assumiram sua condição pejorativa de contribuintes para o caos social, mas que se colocam no papel de agentes reacionários a todo mal que causaram, direta ou indiretamente.

Como não há maneiras viáveis de uma organização sozinha se desvencilhar dos males que o modelo capitalista trouxe com o domínio hegemônico da economia mundial e longe de ser apenas uma crise de consciência, a comunicação de atitude parte do princípio da emergência, ou seja: se ainda existe algo de bom que possa ser feito, que seja feito o mais rápido possível e com maior intensidade. Não há tempo para filosofias ou análises conjunturais complexas e nem é esse o papel das empresas, as análises conceituais e científicas cabem aos pesquisadores $e$ às universidades, que investigam com maior profundidade o assunto.

De forma independente ou, algumas vezes, integrada, torna-se cada vez maior o número de empresas e de profissionais que incutem, dentro da filosofia corporativa em que atuam, projetos de comunicação de atitude que já estão repercutindo positivamente, servindo como base educacional para a formação de uma consciência mais saudável, motivando novas pessoas a vivenciarem essa prática pela possibilidade da inclusão social nesses projetos.

A comunicação de atitude adota, além do discurso publicitário mais mercadológico, novas posturas sociais diferentes daquelas institucionalizadas pelo marketing social, que têm prazo de validade e muitas vezes acontecem distantes do ambiente onde se insere a empresa. $\mathrm{O}$ que existe nessa postura empresarial e que se assemelha muito à definição do Terceiro Setor é que a comunicação de atitude comporta a questão do retorno financeiro advindo de uma responsabilidade social que se junta ao sucesso da empresa.

As ações de comunicação partem, dessa forma, das atitudes movidas por convicção pessoal de dirigentes, pela capacitação profissional dos gestores de comunicação e marketing, por valores e princípios adotados em uma nova administração, por inteligência empresarial $e$ mesmo pela necessidade de mudança social em determinadas regiões. Afinal, o grande propósito do pensamento que permeia a comunicação de atitude é o interesse em diminuir a pobreza e as diferenças socioeconômicas encontradas em âmbito regional, porque de nada adianta para uma empresa que vende produtos e serviços oferecê-los a um número excessivo de pessoas que futuramente terão mínima condição financeira e, consequentemente, menor poder de compra.

Dentro dessa filosofia empresarial que movimenta as ações de comunicação, o objetivo central do discurso publicitário é atingir a consciência coletiva e minimizar desequilíbrios socioeconômicos que afetam também o meio ambiente. No entanto, devem-se distinguir com maior precisão as diferenças que separam a definição de comunicação de atitude da definição de marketing social. "O marketing social é a contribuição em projetos sociais visando única e exclusivamente o aprimoramento de sua imagem comercial" (GARCIA, 2002, p. 29). Essas atividades geralmente têm prazo de validade, estão inseridas dentro de um plano de marketing voltado para um período específico ou para um semestre de atividades comerciais, que envolvem especialmente ações de fortalecimento de marca. 
A comunicação de atitude envolve, sobretudo, o conceito de sustentabilidade, e não se mistura com assistencialismo.

\section{Por uma nova postura}

Com base nos argumentos que foram apresentados e tomando como referência mais específica a incorporação de valores culturais ao discurso da propaganda, torna-se importante analisar os estudos de Bakhtin (1979) que permitem conhecer o princípio constitutivo da linguagem, em qualquer que seja o campo, por meio das relações dialógicas.

As relações dialógicas, no entanto, são interpretações mais esclarecidas, contendo a ideia de relatividade da autoria individual $e$, consequentemente, o destaque do caráter coletivo, social da produção de ideias e textos, que, no caso da propaganda, relaciona-se por meio do discurso publicitário e suas múltiplas ligações com outros textos, constituindo uma coerência gramatical altamente complexa e indissociável da imagem de organização.

Para reforçar a importância do diálogo no processo de interação social, levam-se em consideração as palavras de Maria Celeste Marques que explicam essa relação de causa sob uma óptica mais aprofundada, do ponto de vista que Bakhtin propunha com o dialogismo:

Enfatizei que Bakhtin considera o dialogismo como o princípio constitutivo da linguagem e como a condição do sentido do discurso. Dessa forma, o discurso não é individual tanto pelo fato de que ele se constrói entre, pelo menos, dois interlocutores que, por sua vez, são seres sociais; como pelo fato de que ele se constrói como um diálogo entre discur- sos, isto é, mantém relações com outros discursos. O discurso, para Bakhtin, é uma "construção híbrida", (in)acabada por vozes em concorrência e sentidos em conflito (MARQUES, 2001, p. 4).

Diferentemente da mecanização dos processos estratégicos da propaganda, a sociedade não é lógica e muito menos previsível e não funciona exclusivamente à base de estímulos propostos pelo marketing, via de regra, orientado por experiências de pesquisas comportamentais ou de consumo. Logicamente que experiências já vivenciadas ajudam a encontrar atalhos na solução de problemas de comunicação, tomando como base eventos já vivenciados. No entanto, a propaganda serve para realizar tarefas de comunicação com a sociedade, em velocidade e volume maiores que os obtidos por quaisquer outros meios.

Se entendermos o verbo vender num sentido amplo, generoso, de levar aos outros a mensagem capaz de interessá-los em determinada ação, a finalidade principal da propaganda, então, é vender. Ao convencer os pais da necessidade de vacinar seus filhos, a propaganda vende a idéia preservadora da saúde infantil. Quando aponta os proveitos do pagamento de impostos, vende uma noção que favorece o contribuinte e a coletividade. Não devemos cair no excesso de pensar que apenas a propaganda pode vender determinada mercadoria. Ela ajuda, estimula, motiva a venda. Mas sem os demais fatores essenciais: qualidade do artigo, apresentação atraente, facilidade de distribuição, condições de preço entre outros, seria insensato pensar que a mensagem publicitária alcançaria os objetivos desejados (SINPROP 3 , 2003).

\footnotetext{
${ }^{3}$ GRUPO TENDÊNCIAS DA PUBLICIDADE CONTEMPORÂNEA, disponível em: < http://www.tpublicidade.blogger.com.br>. Acesso em: 20/09/2007.
} 
Portanto, o presente estudo apresenta a propaganda sob um novo prisma, contribuindo para a interação social no desenvolvimento de novas atitudes sociais. Essa postura impõe o termo comunicação de atitude e, para que isso ganhe autenticidade e autonomia, é necessário que as empresas entendam a propaganda a partir de dez vetores estratégicos que condicionam a credibilidade desse discurso, desde que se respeitem esses elementos em uma estrutura dinâmica, aberta e participativa, mantendo os respectivos preceitos interna e externamente nas políticas públicas de sua organização:

\section{I - Comunicação de atitude não} especifica público-alvo: $\mathrm{Na}$ comunicação de atitude, o discurso publicitário, sem querer generalizar, ignora a necessidade de definir um target, os processos não podem ser simplificados a um nicho de mercado específico. Com isso, valoriza-se a complexidade social que se constitui por diferentes grupos (stakeholders) sem que exista a necessidade de exclusão social. Do mesmo modo, não exclui também outras áreas de conhecimento diferentes da propaganda $e$ marketing, que podem contribuir de alguma forma com a amplitude das ações de responsabilidade social.

II - Os projetos são perenes: Imagine-se que cada habitante do Brasil produz, por ano, em torno de 25 quilos de sacolas plásticas. Uma montanha de plástico que se acumula nos lixões de todo o país. Em lojas, supermercados, padarias, bancas de jornais, etc. Por uma questão de hábito, os produtos são transportados nesse meio, que depois é descartado, causando um grande problema ambiental. Dessa forma, uma ação social sazonal não resolveria o problema e muito menos minimizaria a degradação causada por esse hábito no meio ambiente. Por isso, a comunicação de atitude é um projeto de comunicação perene e, mesmo que a empresa ou a organização que tenha criado esse projeto deixe de existir, o projeto deve conter pilares de sustentabilidade que possibilitem sua continuação por outra empresa, grupo ou corporação que deseje adotá-lo, como uma postura de atitude também.

\section{III - O foco das ações está na} aprendizagem e na educação: A comunicação de atitude, diferentemente da propaganda que objetiva diretamente a venda, atua com outro caráter sem excluir a promoção de sua imagem, mas também ensina, educa, informa, conscientiza e se engaja socialmente. Ao deixar de trabalhar com target, a comunicação de atitude se apoia em públicos de interesse, concentrando-se em maneiras de integrá-los com a filosofia de melhoria na qualidade de vida. Portanto, a comunicação de atitude deve contemplar, em seu planejamento, projetos com aulas expositivas, leituras, palestras, treinamentos, cursos e principalmente a possibilidade de exercer ações práticas junto com a sociedade. Com isso, as empresas que adotarem, na sua filosofia organizacional, a comunicação de atitude precisam, antes de tudo, ceder parte de seu horário de trabalho às práticas instrumentais que integram funcionários - sociedade em uma nova consciência.

\section{IV - Mecanismos de controle e} mensuração dos resultados: Para que exista sustentabilidade, torna-se necessária a criação de ferramentas que comprovem cientificamente os efeitos benéficos dessa ação. Para isso, faz-se necessário entender que sustentabilidade é um conceito sistêmico, relacionado à continuidade dos aspectos econômicos, sociais, culturais $e$ ambientais da sociedade, condição de uma sociedade ou de um processo de desenvolvimento que consegue a satisfação de suas necessidades, sem comprometer os bens da natureza e sem lesar o direito das gerações futuras de verem atendidas, também, as suas necessidades, além de herdarem um planeta sadio. Para que isso aconteça de fato, as empresas devem criar mecanismos de controle e mensuração de resultados que comprovem, por meio de ferramentas, os resultados de suas ações. Isso pode vir a partir 
do desenvolvimento de relatórios técnicos assinados por entidades especializadas, pesquisas, laudos científicos, gráficos de desempenhos, exames laboratoriais, entre uma série de outros instrumentos viáveis, de acordo com o desenho de cada projeto.

V - Interação social: Na contramão dos processos cristalizados de produção publicitária, as empresas que investem parte de seus recursos em investigações na relação dos processos de integração social já descobriram novas linguagens para dialogar com seus grupos de interesse e, diferentemente do caráter interesseiro do discurso publicitário, conseguem evoluir na sua relação com a sociedade. Mesmo porque a publicidade é, sobretudo, um grande meio de comunicação com a massa e, por ser parte de uma atividade contratada, paga com a finalidade de fornecer informações, deve desenvolver também atitudes e provocar ações benéficas para o anunciante. Mas o que ocorre geralmente é que, para vender seus produtos e serviços, a propaganda tradicional exclui pessoas e segmenta públicos que constituem parte integrante da massa crítica, que é responsável por eleger a preferência por determinadas marcas.

\section{VI - Não existem doações e even-}

tos esporádicos: Entender o que é sustentabilidade torna-se o grande desafio do momento, porque muitos conceitos transformam-se em artigos de moda na comunicação mercadológica, afetando principalmente as estruturas do discurso publicitário, quando legitimamente destinam seu repertório para práticas de desenvolvimento socioambiental. Na comunicação de atitude, a melhor definição para sustentabilidade é aquela que envolve o uso das funções vitais do ambiente biofísico de maneira a permanecer disponível indefinidamente. Entende-se, sobretudo, que a palavra "indefinidamente" elimina qualquer tipo de doação, caridades por compaixão ou ações de arrependimento momentâneo. Doações não acontecem regularmente e não suprem as necessidades complexas do ambiente. Com isso, o discurso da propaganda leva ao conhecimento da sociedade as posturas sustentáveis que um determinado grupo adota para desenvolver uma determinada região, satisfazendo as necessidades presentes, sem comprometer a capacidade das gerações futuras de suprir suas próprias necessidades. A comunicação de atitude, em vez de fazer doações e manter grupos sociais em estado de dependência, deve ensiná-los a buscar seus recursos próprios, com autonomia.

\section{VII - Postura de comunicação or-}

ganizacional: A comunicação organizacional ignora as relações de comunicação com práticas exclusivas para servir os interesses de compra e venda de produtos, buscando atingir quase sempre o público externo. Com a comunicação organizacional figura-se a necessidade de incorporar a função do gestor de comunicação, que assume as responsabilidades de promover e criar novos valores para a empresa, aliados à missão e à visão. Assim, a comunicação organizacional, além de harmonizar a comunicação interna com a externa, provoca novas atitudes de relacionamento corporativo, em que os funcionários dão o exemplo. Esse aspecto torna-se fundamental porque, quando existe a mentalidade de incorporar um gestor de comunicação ao ambiente interno da empresa, criam-se, consequentemente, projetos que se encaixam perfeitamente na identidade cultural da empresa, criando um clima motivador no seu ambiente interno, que educa, constrói novos valores e valoriza indivíduos. Essa postura serve também para produzir comunicação para o mercado organizacional e criar valores no mercado consumidor por meio da propaganda institucional.

\section{VIII - Foco nas pessoas, não em}

produtos: Apesar de não perder de vista as questões relevantes ao marketing, tão vitais para a sobrevivência de qualquer empresa, a comunicação de atitude deve priorizar os resultados projetados pela estratégia corporativa que são produzidos pelas pessoas talentosas que otimizam suas contribuições, porque se identificam 
afetivamente com a complexidade dos projetos que são desenvolvidos para a empresa, e não pela empresa. Dentro do modelo de negócio corporativo, alguns elementos são de fácil identificação e de grande importância. As estratégias corporativas definem, em síntese, qual trabalho de "atitude" deverá ser feito pela empresa, como esse trabalho será feito na sociedade e quais lideranças estarão envolvidas nesse processo. Do mesmo modo, deve-se definir quem vai conduzir a força de trabalho por meio dos processos de responsabilidade social e qual contingente de pessoas deverá ser integrado, tanto internamente quanto externamente, para atingir os objetivos estratégicos propostos pela gestão.

IX - Práticas internas e externas: $\mathrm{Na}$ atual conjuntura, o discurso publicitário já não consegue se democratizar com tamanha intensidade, comparado aos processos anteriores, $e$, na intenção de modernizar e se igualar aos novos conceitos do marketing recém-trazidos dos Estados Unidos e a tudo que foi pregado institucionalmente na sociedade de consumo, fez com que diminuísse a capacidade de mesclas com outros gêneros da cultura, muito embora a publicidade tenha sido reconhecida como algo de prestígio e poder. Portanto, não existe a mínima possibilidade de se praticar um discurso minimalista com ênfase no consumo e nos recursos de captação de novos clientes. $\mathrm{O}$ discurso publicitário deve atender as exigências de complexidade que recaem sobre o mundo moderno e competitivo. Há uma grande necessidade de se praticar uma comunicação diferente daquelas massificadas pelas grandes mídias convencionais $e$, principalmente, de criar novas estruturas de diálogo $e$ interação social.

\section{X - A nova linguagem não pode}

ser global: Uma campanha publicitária que é veiculada na mídia de massa ou em qualquer outro meio de comunicação não pode atuar como fenômeno isolado, assumindo a responsabilidade principal pelo sucesso da imagem de uma corporação. O valor de uma empresa está condicionado a um grande sistema, denominado, por Iuri Lotman, semiosfera. O semioticista russo define semiosfera, em analogia ao conceito de biosfera, como o funcionamento dos sistemas de significações de vários tipos e níveis de organização, ou ainda como "o espaço semiótico fora do qual é impossível a existência da semiose" (LOTMAN, 1996, p. 24).

\section{Conclusão}

Essas observações contemplam a força que a propaganda exerceu no subconsciente das pessoas e nas relações humanas para uma construção de conceito baseada no discurso do sucesso, exterior à cultura do Brasil, pois, como afirma Eleseo Colón: "La publicidad fue a primera prática discursiva de la cultura burguesa en legitmar los principios de una psicologia científica de la recepción" (COLÓN, 1996, p. 51).

A visão da propaganda inclina-se mais para os aspectos de persuasão, sem se adequar às questões culturais, $e$ não pode anular outras formas de relacionamento com o consumidor. Novas formas de linguagens já estão emergindo e trazem consigo elementos sobre como desenvolver posturas mais éticas, de responsabilidade e autocontrole, ao mesmo tempo em que não descuidam de fatores de natureza prática necessários ao sucesso comercial.

Há, portanto, no campo científico, pesquisas que comprovam a existência de uma terceira linguagem, que tem como objetivo dialogar entre duas linguagens para gerar uma terceira, no interior da qual se podem relativizar ambas sem minimizar os efeitos para os quais são indispensáveis. A primeira linguagem é a de marketing, que tem o objetivo de vender satisfazendo as partes do processo; a segunda linguagem entende-se que é a propaganda, num tom institucional com o papel de manter um contato não comercial com o público; e a 
terceira linguagem estabelece um debate acerca dos valores da organização que trata seus clientes não como simples consumidores, mas na investidura de um cidadão consciente, capaz de tomar decisões sobre o que se passa a sua volta, principalmente nas questóes de consumo.

Assim, profissionais de comunicação devem orientar suas ações no sentido de interpretar as questões sociais - com destaque para as culturais - e ecológicas e acrescentar aos consumidores uma preocupação socialmente responsável. Devem estabelecer novos conteúdos e formas operacionais de produção de sentido $e$ de promoção, para obter definições claras $e$ coerentes sobre o equilíbrio entre a oferta $e$ o consumo. Uma forma promocional com um discurso mais racional e didático deve influir no

\section{REFERÊNCIAS}

AL RIES; TROUT, Jack. A queda da propaganda: da mídia paga à mídia espontânea. Rio de Janeiro: Campus, 2002.

\footnotetext{
Revista Comunicação Empresarial, ano 13, n. 47, p. 4, 2o. trimestre 2003.

BAKHTIN, Mikhail. Marxismo e filosofia da linguagem. São Paulo: Hucitec, 1979.
}

CASTELO BRANCO, Renato; MARTENSEN, Rodolfo Lima; REIS, Rodolfo. História da Propaganda no Brasil. São Paulo: T. A. Queiroz, 1990.

CHOMSKY, Noam. Novas e velhas ordens mundiais. São Paulo: Scritta, 1996.

COLÓN, Eliseo Zayas. Publicidad y hegemonía: matrices discursivas. Buenos Aires: Norma, 2001.

MASLOW, Abraham H. Motivation and personality. New York: Harper \& Row, 1954. p. 80-106.

GARCIA, B. O marketing social é a contribuição em projetos sociais visando única e exclusivamente o aprimoramento de sua imagem comercial. São Paulo/Petrópolis: Instituto Ethos, 2002. p. 29. processo mercadológico, desde a produção e distribuição de bens e serviços até a comunicação com os públicos da instituição.

Portanto, a comunicação de atitude parte inicialmente do talento criativo, indexando a capacidade que o gestor de comunicação tem de se apoiar em outras áreas do conhecimento e, sobretudo, em outros conceitos que são adquiridos por meio da ciência em interatividade com a sua experiência de vida, denominada de cultura. Afinal, a propaganda nada mais é do que uma ferramenta de marketing que sempre será utilizada para ditar se um produto ou marca terá sucesso de aceitação $e$ compra por parte do público. Muitas vezes, esse produto pode estar encoberto por uma marca, mas o objetivo final sempre é a promoção.

GRACIOSO, Francisco. 50 anos de vida e propagandas brasileiras. São Paulo: Mauro Ivan Marketing Editorial, 2001.

HOPINKS, Claude. Scientific advertising. 5. ed. Nova York: Crown Publishers, 1966. Original text by Claude Hopinks Copyrighted 1923 by Crown Loard \& Thomas, New York City.

KOTLER, Philip. Administração de marketing. 4. ed. São Paulo: Atlas, 1996.

LASSWELL, Harold D. A estrutura e a função da comunicação na sociedade. In: COHN, Gabriel (Org.). Comunicação e indústria cultural. 5. ed. Trad. Gabriel Cohn. São Paulo: T. A. Queiroz, 1987.

LOTMAN, Iuri M. Semiótica de la cultura y del texto. In: La semiosfera I. Trad. Desiderio Navarro. S.1.: Ediciones Cátedra, 1996.

; USPENSKII, Bóris. Sobre o mecanismo semiótico da cultura. In: _._. Ensaios de semiótica soviética. Trad. Vitória Navas. Lisboa: Horizontes, 1981.

MARQUES, Maria Celeste Said. Vozes Bakhtinianas: breve diálogo - ano I, n. 36. Porto Velho: Universidade Federal de Rondônia, 1999.

SHARLACH, Jeffrey. Conexão interativa. Revista Marketing, São Paulo, ano 41, n. 413, jun/2007.

Texto recebido em 30 de julho de 2009. Texto aprovado em 25 de setembro de 2009. 